\title{
Three new species of Alchemilla (Rosaceae) from northern Britain
}

\author{
Mark Lynes \\ Doncaster, South Yorkshire, UK
}

\begin{abstract}
*Corresponding author: maslyni@gmail.com
\end{abstract}
This pdf constitutes the Version of Record published on $16^{\text {th }}$ September 2021

\begin{abstract}
Three new species of Alchemilla (Rosaceae) are described, two from the Northern England and a third from the highlands of Scotland. Alchemilla falsadenta and Alchemilla mebii are described from the Yorkshire Dales. Both belong to the Series Vulgares Buser, Subseries Subglabrae H. Lindberg, although the latter could conceivably be placed in Subseries Hirsutae H. Lindberg. Alchemilla neomanifesta of the Series Vulgares, Subseries Hirsutae is described from Ben Lawers National Nature Reserve.
\end{abstract}

Keywords: Grass Wood; Malham Tarn; Yorkshire Dales; Ben Lawers; Margaret Bradshaw

\section{Introduction}

This is the second in a planned series of papers describing a small number of previously undescribed UK and Scandinavian Alchemilla taxa.

In the 1940s and 1950s Margaret Bradshaw (MEB) travelled extensively through northern Britain collecting Alchemillas. Subsequent survey work in Yorkshire convinced her that when it came to $A$. wichurae, all was not quite as it was assumed to be.

Latterly her attention was concentrated on Alchemilla filicaulis Buser as she worked towards her doctorate. In the course of this work a number of specimens were collected of plants which did not quite fit the norm for filicaulis. Brief mention of these was made in the triptych of Watsonia papers (Bradshaw 1963a; 1963b; 1964). However, the PhD thesis on which these papers are based goes into considerably more detail. Unfortunately, few of the specimens collected during this period survive. A series of conversations with MEB around 2010 convinced me to search for the most prominent of her finds and this paper is the result.

\section{A/chemilla falsadenta M. Lynes sp.nov}

TYPE. Sparsely vegetated tracksides in Grass Wood, Mid-west Yorkshire (v.c.64), 23 June 2016, 200-300 m altitude SD986654 (holotype: LES; Isotype: herb. M. Lynes). Vernacular name - False-toothed Lady's-mantle.

Plant medium-sized, low, spreading. Basal leaves reniform to near heptagonal. Lamina to $122 \mathrm{~mm}$ wide, $111 \mathrm{~mm}$ deep. Dark green adaxially, edged silvery-white. 
Glabrescent; teeth hairy or not, with long, whitish plumes from tip; hairs may extend to outer lobe and/or down folds. Veins often brighter, angled slightly greater than $45^{\circ}$. Paler abaxially, glabrous. Veins moderately pubescent to at least $1 / 2$ to $2 / 3$ from lobe edge. Usually 9 lobes, concave, undulating; rounded to triangular, lobed to $1 / 3$, usually less, with slit between or not. Basal sinus closed to overlapping. Teeth 103213 per leaf, shallow, unequal, distinctly spaced. Broadly triangular to aquiline mammiform; largest 1.58 to $5.56 \mathrm{~mm}$ deep ( 2.13 to $7.26 \%$ of the lamina radius), 1.36 to $5.17 \mathrm{~mm}$ wide. Apical tooth of similar height, 1.55 to $2.74 \mathrm{~mm}$ wide (3.68 to $8.40 \%$ of the lobe width; 1.13 to $2.04 \mathrm{~mm}$ deep (1.77 to $3.87 \%$ of the lobe width). Petioles slender, rounded to $274 \mathrm{~mm}$ long, sparsely to moderately hairy. Stem procumbent, 1.5 to $2.2 .5 \times$ longest petiole, moderately hairy up to/including $2^{\text {nd }}$ internode, $3^{\text {rd }}$ internode usually glabrous or nearly so, little branched. Few leaves, similar to basal ones, shortly petiolate. Inflorescence wide, flowers in lose, fewflowered bunches. Flowers yellow-green, 2.4 to $3.1 \mathrm{~mm}$ wide. Pedicels 1.7 to 3.4 $\mathrm{mm}$ long. Hypanthium glabrous, obconic. Sepals broadly ovate-acuminate. Epicalyx segments narrowly and sharply triangular, significantly narrower than sepals. Sepals glabrous, with occasional hair from tip. Stipules of basal leaves whitish, tinged green distally, shallowly denticulate at apex, 4-9 teeth per lobe. adpetiolar cleft 7-8 mm deep, 5-9.5 mm wide at apex, lobes 4-4.6 $\mathrm{mm}$ wide, $16-24 \mathrm{~mm}$ in length. All pubescence adpressed.

In the field the dark green colouration of the upper-leaf contrasting with the white hairs on, and emanating from, the teeth; the often near heptagonal leaf shape; often distinctly angular-looking lobes which may be twisted and contorted; and the often spiky-looking teeth, help to give the plant a very distinctive appearance.

\section{History}

Long known from Grass Wood, as a population of plants most closely resembling A. wichurae (Buser) Stephánsson amongst the species recognised as British at that time It is to the considerable credit of MEB that from at least 1958 she had her doubts as to this identification. Alerted by her then certainty that this plant was something undescribed, I visited the site on 29 May 2010, and on entering the wood almost immediately located what was clearly the same plant. Multiple visits over the ensuing decade, however, were required before I was in a position to formally describe it.

\section{Habitat}

The type locality, and the only locality from which it is currently known, is the Yorkshire Wildlife Trust reserve of Grass Wood, Grassington, a semi-natural broadleaved woodland on the carboniferous limestone of upper Wharfedale (Lee, 2015). Here it grows with other A/chemilla taxa, including predominantly $A$. glabra Neygenfind and $A$. xanthochlora Rothmaler. It is found along the bare edges of many of the tracks running through the wood, with particular concentrations at some of the major junctions where people walking in the wood often cut the corners and by so doing depress overall vegetation growth.

\section{Differences from other species}

Plants of this taxon have quite understandably previously been referred to $A$. wichurae. However, it is actually much more similar to the closely related Swedish 
endemic $A$. oxyodonta (Buser) C.G. Westerlund. $A$. falsadenta is highly polyploid, having a similar chromosomal mass $-0.65 \mathrm{pg}$ - to $A$. oxyodonta and much higher than the relevant figure for $A$. wichurae (0.42) (the late Gerold Hügin, pers. comm.).

From $A$. wichurae it can be told by a combination of features. However, the appearance of the plant is usually sufficiently different to draw attention to it, with its dark green leaves edged contrastingly silvery-white (Fig. 1), the lobes twisted in varying directions, the teeth spiky, somewhat unkempt and contrastingly pale.

The teeth are shallower, more superficial, yet broader than in $A$. wichurae and there are more of them. They do not typically appear incurved, appearing straighter and consequently sharper. They are more irregular in both size and shape. The pedicels are slightly, yet significantly, shorter, and the flowers are smaller. On the inflorescence, the $2^{\text {nd }}$ internode is noticeably shorter, and any hairs do not extend beyond the $3^{\text {rd }}$ internode; in $A$. wichurae pubescence may extend up to/including the $4^{\text {th }}$ internode. The inflorescence of falsadenta is usually also stouter, wider and more open

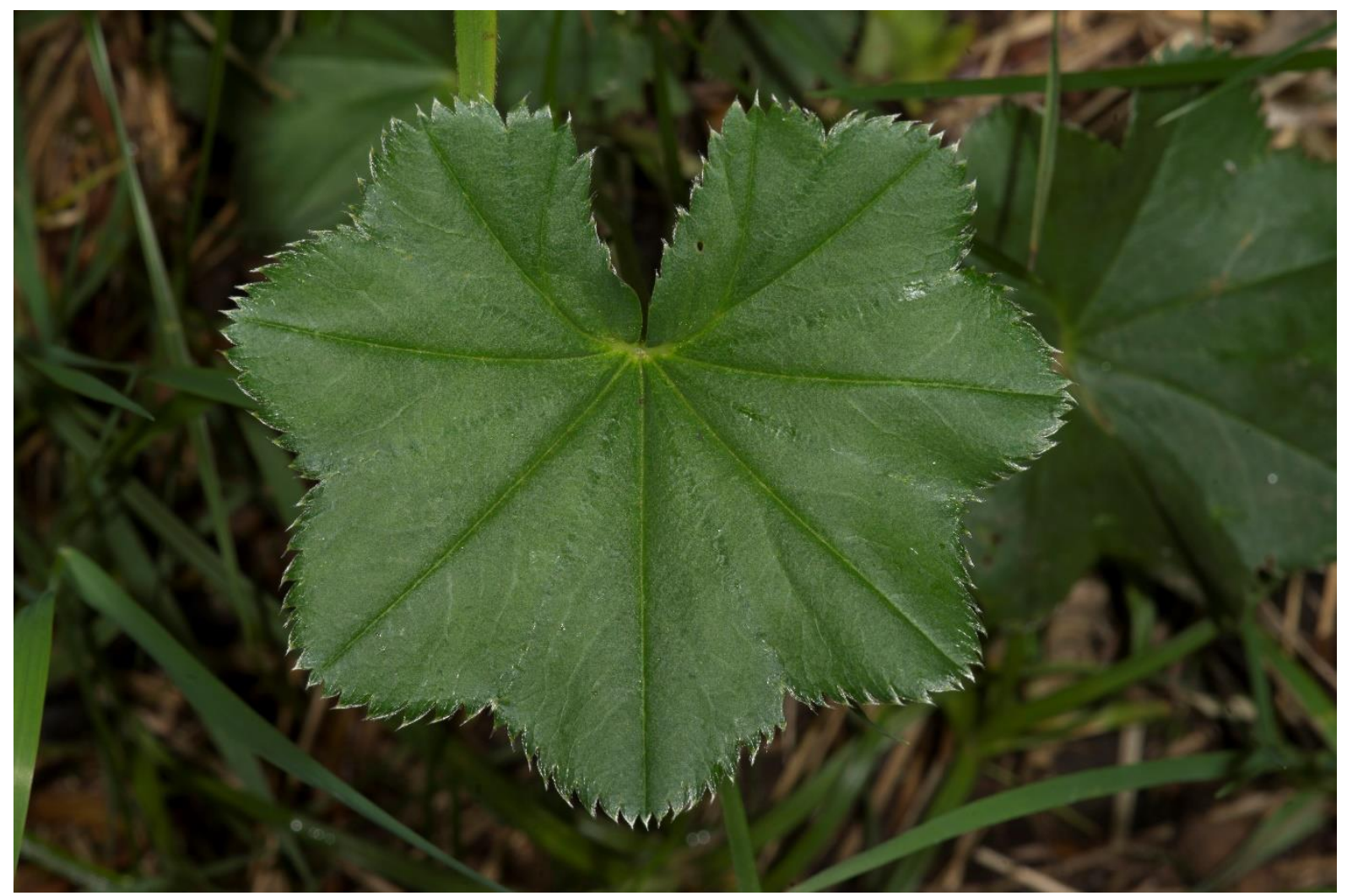

Figure 1. Leaf of A/chemilla falsadenta showing hairy, contrastingly silvery-white, teeth

The endemic Swedish taxon $A$. oxyodonta proved a seductive solution to the conundrum which had for so long been the Grass Wood Alchemilla. Photographs of the Swedish plant appeared very similar and for some time I entertained what seemed a very real possibility, that $A$. oxyodonta was not endemic to Sweden after all. Examination of herbarium specimens - both here and in Sweden - served only to muddy the waters. It was obviously necessary to see $A$. oxyodonta in its native country and - more than that - in its locus classicus, the very few woodlands in 
Hermanboda, Medelpads lan, Sweden, where it grows. In June of 2017 - as part of a much wider exploration of undescribed Swedish Alchemilla - I visited the woodland of Hermanboda to study the species in situ; plants were subsequently seen in the environs of Ostersunds also. One perhaps unexpected consequence of the trip was that $A$. oxyodonta was found to be much commoner in its Swedish heartland than had previously been understood - see, for example Lidberg \& Lindström (2010) thus permitting limited collection of living material which was subsequently grown on in my North Lincolnshire garden, allowing direct comparison with both $A$. wichurae and $A$. falsadenta for the first time.

As with $A$. falsadenta, the leaf of $A$. oxyodonta is distinctly heptagonal in appearance, only more strongly so. The lobing is shallower, the leaf flatter, any undulations shallower and more flowing. There are fewer teeth, and these are deeper, more upright and much more regular; the latter feature contrasting markedly with the decidedly uneven teeth of $A$. falsadenta (Fig. 2). The main veins of $A$. oxyodonta are almost invariably pubescent for their full length, less often for $1 / 2$ to $3 / 4$ from the edge of the leaf: the near opposite of $A$. falsadenta.

Both the flowers and the pedicels on which they sit are distinctly smaller/shorter; they are held in denser, less open, clusters. The whole inflorescence of $A$. oxyodonta is shorter, narrower and stockier, the stem - and particularly the branches - thicker, the main inflorescence branches invariably held at a much narrower angle - less than $45^{\circ}$ - than in $A$. falsadenta. It is narrower and less branched than in $A$. falsadenta, whch typically has a noticeably wider, much more lax inflorescence

The basal leaf stipules of both taxa are ostensibly similar in appearance, both are denticulate, more or less rectangular in shape and with the lobes held in a relatively shallow ' $\mathrm{V}^{\prime}$ ', angled at less than $45^{\circ}$. However, the stipules of the two taxa are usually quite different in appearance. The stipule lobe teeth of $A$. oxyodonta are obvious, relatively shallow yet distinct, narrow to broad on apices with noticeably rounded sides, and with the lobes strongly tinted green, up to $3 / 4$ of the depth from the base, sometimes slightly tinted pink in places at the base In $A$. falsadenta the lobes are whiter overall, usually lacking both the prominent, contrasting, apical, green tinge and any hint of pink at the base. However, on occasions, in cultivation at least - and here quite unlike $A$. oxyodonta - the whole of the individual stipule lobe may be strongly suffused pink. The teeth are slight and typically inconsequential; so much so they are often hard to distinguish at all. The basal stipules of $A$. wichurae are much more like those of $A$. oxyodonta, although the apical teeth are even more distinct and noticeably deeper. Further differences are to be found in the area at the base of the adpetiolar cleft. In both $A$. falsadenta and $A$. wichurae there is usually no area of concrescence. In $A$. oxyodonta there is usually a short section of concrescence, of no more than $1 \mathrm{~mm}$

The teeth of the uppermost complete leaf/stipule of $A$. oxyodonta are fewer in number than both $A$. falsadenta and $A$. wichurae, with typical counts as below:

A. falsadenta - up to 34

A. wichurae - up to 30

A. oxyodonta - up to 21

Additionally, the number of teeth on the central lobe of the uppermost complete leaf/stipule also differs, as follows:

A. falsadenta - No more than 5 (usually 3 to 5 ) 
A. oxyodonta -3 to 7 (much more variable)

A. wichurae -5 to 8 (usually 5 )

Finally, in cultivation $A$. falsadenta differs markedly from both these species. Both $A$. oxyodonta and $A$. wichurae remain true to their wild-growing congeners, the former staying low and rather weak-looking, the latter resembling the more luxuriant forms found in parts of the Scottish Highlands, in areas where large herbivores have been excluded. $A$. falsadenta, in contrast, behaves nothing like its type, producing large, robust, almost bushy plants, quite unlike the oxyodonta-like plants in Grass Wood.

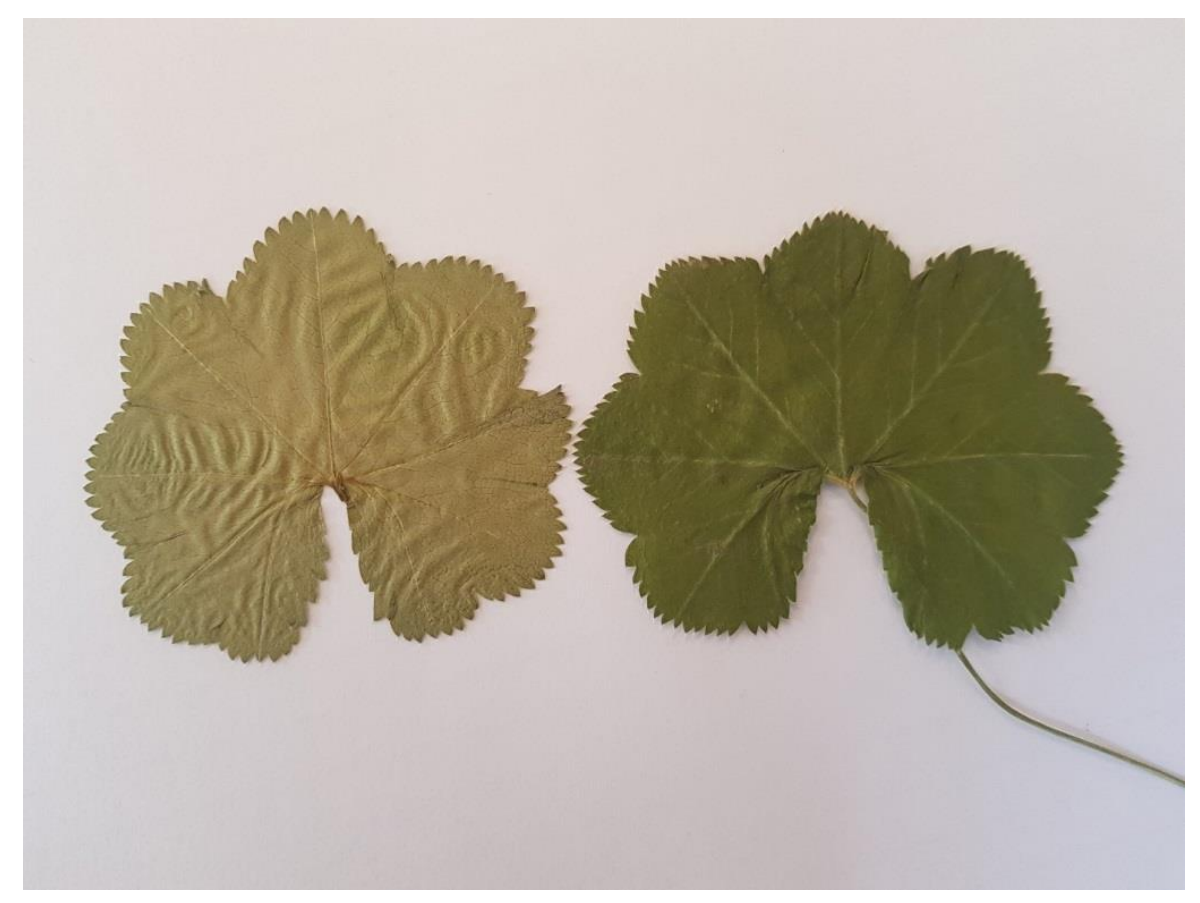

Figure 2. Leaves of Alchemilla oxyodonta (I) and A. falsadenta ( $r$ ) showing differences in toothing

\section{Etymology}

Named on the basis of the very close similarity to $A$. oxyodonta. The specific epithet honours that taxon - 'oxyodonta'meaning sharp-toothed - whilst taking advantage of the linguistic playfulness inherent in the constructed language Esperanto. The English name is both a literal translation of the specific epithet, whilst also alluding to the fact that the species has long been confused with other species within the $A$. wichurae complex.

\section{Conservation status}

A. falsadenta is classified as IUCN Threat Category "Endangered" (IUCN 2001) due to the small known population size. There appears to be no immediate threat to its survival, albeit the known population is potentially vulnerable to woodland succession, trampling and changes in woodland management. 


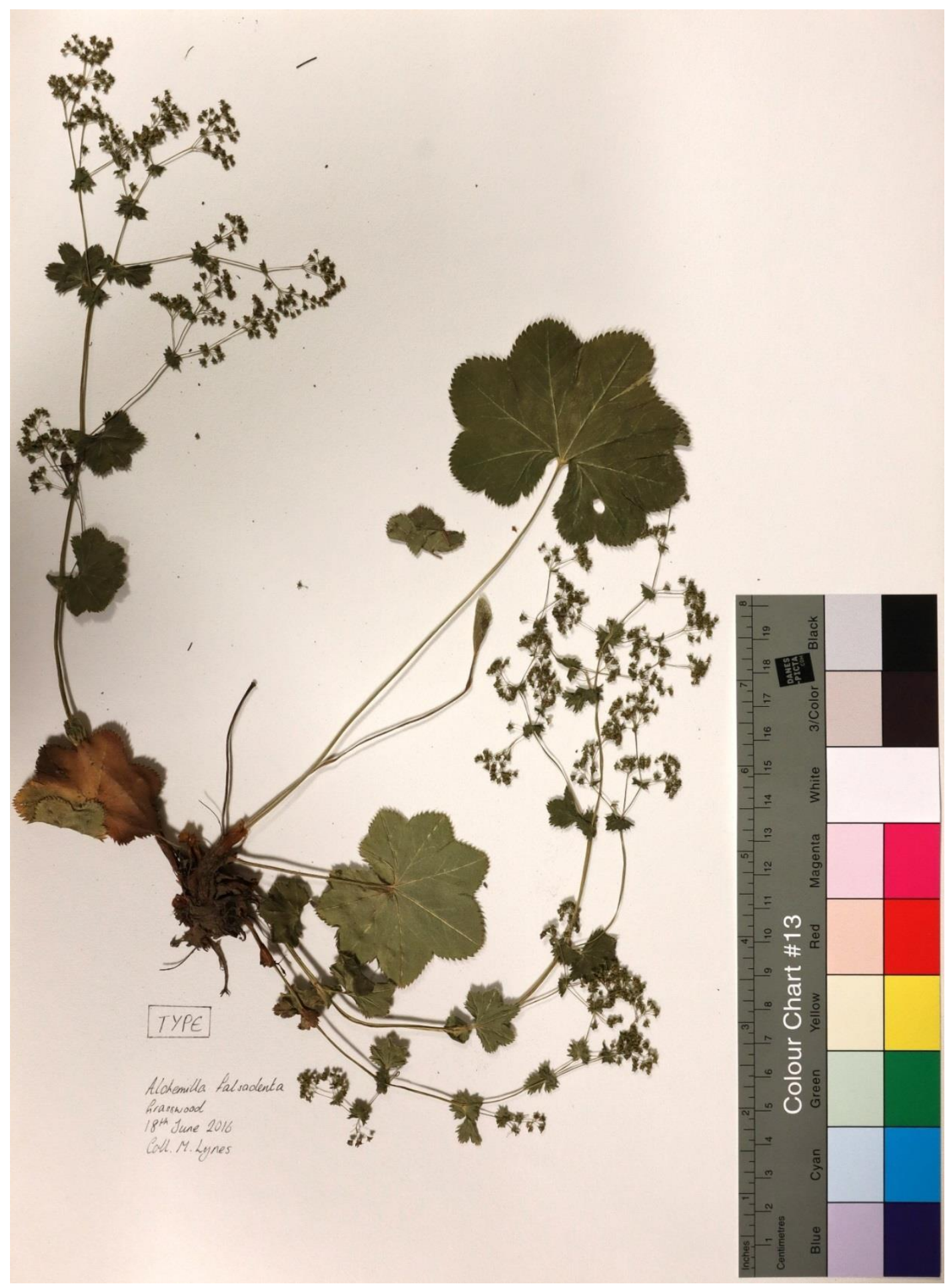

Figure 3. Holotype of Alchemilla falsadenta (LES)

Alchemilla mebii M. Lynes sp.nov.

TYPE. Species-rich grassland, Malham Tarn, Mid-west Yorkshire (v.c.64), 1 July 2020, c.400 m altitude. SD8967 (holotype: LES)

Vernacular name - Margaret's Lady's-mantle

Plant medium-sized, upright. Basal leaves near orbicular, to $100 \mathrm{~mm}$ wide, $90 \mathrm{~mm}$ deep. Light, glaucous-green adaxially, sericeous to near glabrous, hairs adpressed to 
more or less erecto-patent. Paler and glabrous abaxially, scattered hairs on teeth and/or lobe edges. Veins densely pubescent for full length, adpressed to erectopatent. Main veins, angled at $c .45^{\circ}$. $7(5)$ lobes, concave, undulating. broad, rounded, 10 to $c .33 \%$ of leaf radius. Sinus between lobes lacking obvious incision. Basal sinus closed to overlapping. Teeth, 99 to 149 per leaf, unequal, distinctly spaced, almost mammiform. Largest 1.2 to $2.7 \mathrm{~mm}$ deep (2.2 to $4.9 \%$ of lamina radius), 1.6 to $3.6 \mathrm{~mm}$ wide. Apical tooth shorter, 1.3 to $1.9 \mathrm{~mm}$ wide (3.7 to $5.4 \%$ of lobe width); 1.0 to $1.4 \mathrm{~mm}$ deep (2.9 to $4.0 \%$ of lobe width). Petioles to $200 \mathrm{~mm}+$, slender, more or less rounded, yellow-green, sometimes tinged pinkish at base. Moderately hairy to glabrescent, adpressed/sub-adpressed to almost erecto-patent. Stem more or less erect, sparsely to moderately pubescent, up to and including $3^{\text {rd }}$ internode, adpressed. 1.5 to $3 \times$ as long as longest petiole. Inflorescence long and spreading, narrow to lax; usually branched, the lowest often noticeably curved. Stem leaves few, similar to basal, shortly petiolate to near sessile. Flowers greeny-yellow, 4.3 to $4.6 \mathrm{~mm}$ wide, in medium-sized, loose fist-shaped heads. Pedicels 1.75 to 2.8 $\mathrm{mm}$ long. Hypanthia campanulate with, distinctly U-shaped base. Glabrous, or with 4 to 6 (to $20+$ ) patent hairs. Sepals broadly ovate-acuminate. Epicalyx segments significantly narrower, broadly lanceolate. All glabrous or nearly so, sometimes with occasional hair at tip. Stipules of basal leaves whitish, green apically. Lobes 4-6 mm wide, $17-23 \mathrm{~mm}$ long, obtuse, denticulate, with long projecting hairs. Edges distinctly pubescent, otherwise glabrous adaxially, abaxially variably pubescent. Adpetiolar cleft 8-10 mm long, 4-6 mm wide. Base of plant green, sometimes pinkish.

In the field the rather pale, glaucous green colouration of the gently undulating upper-leaf usually invites attention (Fig. 4), as do the distinctly U-shaped bases to the hypanthia.

\section{History}

Long known from Malham Tarn, where it was first found by MEB in the 1950s during field work for her PhD. The plant was subsequently forgotten, until a chance conversation with MEB alerted me to its significance. A search in August 2010 soon revealed that the small population known by MEB was still present. The plant was refound in precisely the same area as last seen by MEB; indeed it may even have spread a little in the intervening period.

\section{Habitat}

The type locality and the only locality from which it is currently known, is the National Trust property at Malham Tarn, on the Craven Limestone complex (Lee, 2015). Here it grows in species-rich, calcareous grassland subject to seasonal grazing by cattle, with other Alchemilla taxa, including $A$. glabra, $A$. wichurae and $A$. xanthochlora. 


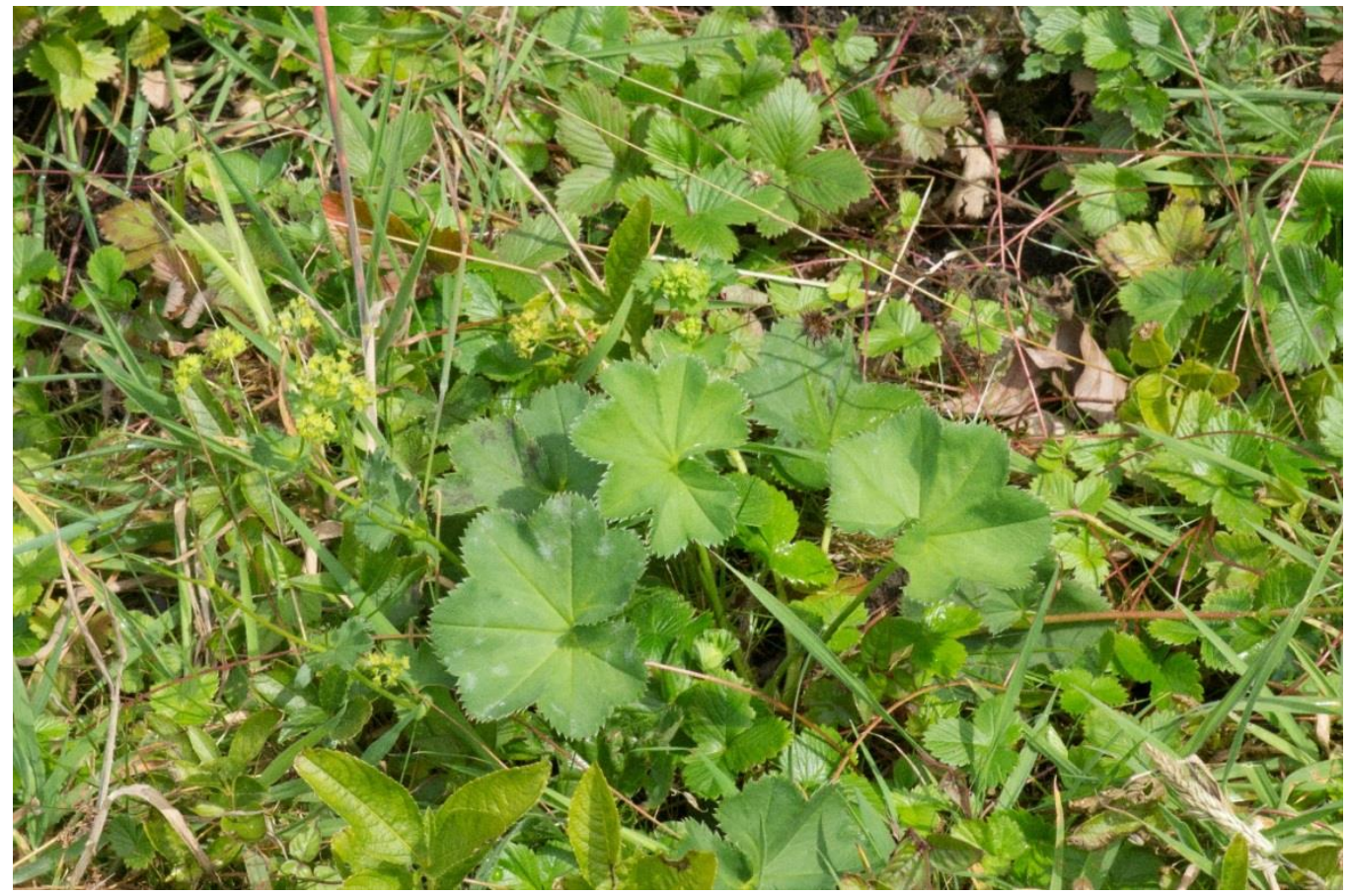

Figure 4. A/chemilla mebii, showing typcial glaucous-green leaf colouration

\section{Differences from other species}

In her 1959 thesis, MEB identified $A$. versipila Buser a widespread plant of the central Alps region as the most similar species. However, $A$. versipila is essentially glabrous and has much more prominently toothed leaves, the teeth large and much more widely spaced. The inflorescence also differs in being noticeably narrow and unbranched.

Early and late season leaves often have much narrower, finer teeth, than summer, or mid-season leaves inviting some comparison with $A$. wichurae. However, that species is quite different, with usually strikingly narrow teeth on paper-like leaves, with any indumentum obviously adpressed and with all hypanthia glabrous.

A visit to the University of Umea herbarium, Sweden, in 2012 first alerted me to the existence of a hitherto undescribed Swedish taxon from Sörmland. Herbarium specimens of this taxon - which I hope soon to formally describe - showed some similarities, not least the presence of patent hairs on some at least of the hypanthia. The Sörmland plant, however, is part of the $A$. obtusa Buser aggregate, the plants having much larger, shallower, leaf teeth and inflorescences which are noticeably lax, with very loose, open heads of few, noticeably small flowers. A visit to the locus classicus in 2016 confirmed the taxon to be really very different.

$A$. mebii could conceivably be confused with $A$. glomerulans Buser, and indeed anecdotally it appears that these plants may have previously been referred to this species at one point in the past. The U-shaped bases to the hypanthia of $A$.

glomerulans are certainly remarkably similar; however, they never show patent hairs and are held in small, tight glomerules. The leaves of glomerulans are also quite different, with prominent yellowing around the veins, folds and leaf edges, with much larger, broader teeth, and leaves which are adpressed pubescent on both leaf surfaces. 
By far the closest in terms of overall appearance are the more glabrescent forms of $A$. filicaulis. However, in this species, any hairs on the stem and petiole are usually clearly patent - or at worst slightly erecto-patent, the indumentum of the petiole as a whole often presenting as rather scruffy. The hypanthia are wine-glass shaped - never U-shaped - and the leaf teeth are quite different in shape, as well as being shallower. The basal leaf stipules are quite different in appearance, much whiter overall - almost translucent, and usually lacking an obvious green distal 'wedge', and with the adpetiolar cleft noticeably wider and deeper. Finally, flow cytometry analysis has shown $A$. mebii to be more highly polyploid than $A$. filicaulis, with a C-value of $0.65 \mathrm{pg}$ compared with $A$. filicaulis at $0.44 \mathrm{pg}$.

\section{Etymology}

The specific epithet honours Dr Margaret Bradshaw both in her initial revelation of this plant as something distinct, and more widely for her great contribution to the study of the UK Alchemilla flora.

\section{Conservation status}

The known population of $A$. mebii is small - no more than 60 plants - and confined to a very restricted area. It is classified as IUCN Threat Category "Endangered" (IUCN 2001) due to the small known population size. There appears to be no immediate threat to its survival. It has previously survived over 50 years of neglected obscurity. For some at least of that period there was little or no management of the site, resulting in some encroachment by various tree species. The site is now under active management, with winter grazing, and its immediate future looks assured.

\section{Alchemilla neomanifesta M. Lynes sp.nov.}

TYPE. Slopes of Creag an Lochain (v.c.88), Mid Perthshire, c.700 m altitude NN5940,23 June 2019 (holotype: LES).

Vernacular name - Revealed Lady's-mantle.

Plant medium-sized, upright. Basal leaves crisp, reniform to near orbicular, virtually flat to distinctly concave. $40-87 \mathrm{~mm}$ wide, $42-68 \mathrm{~mm}$ deep. Yellow-green to bluegreen adaxially, near glabrous. Usually, sparse hairs down folds and teeth, sometimes outer edges of lobes, patent/erecto-patent. Main veins angled $c .35^{\circ}$, to c. $50^{\circ}$. Paler and glabrous abaxially. Main veins, variably pubescent to $3 / 4$ from tip, occasionally full length; hairs densest distally, erecto-patent/patent. 9(7) lobes, broad, obliquely rounded to triangular, $25-33 \%$ of leaf radius. Often obvious notch between lobes. Basal sinus usually narrow. Teeth triangular to aquiline, unequal, distinctly spaced. Largest $3 \mathrm{~mm}$ deep ( $4.5 \%$ of lamina radius), $3-4 \mathrm{~mm}$ wide $(0.8 \times$ to $0.95 \times$ as deep as wide). Apical tooth slightly shorter/narrower. 1-2 mm wide and deep. Petioles 60-90+ mm, rounded, yellow-green; glabrous to moderately pubescent, erecto-patent/patent, long. Stem procumbent/erect, 1.5 to $2.5 \times$ as long as longest petiole; hairy on internodes 1-3 or less, patent/erecto-patent.

Inflorescence narrow, little branched, glabrous. Stem leaves few, similar to basal or, often, flabellate, all shortly petiolate/sessile. Flowers greenish-yellow, in open, fewflowered, fist-shaped monochasia, 3-5 mm wide. Pedicels 1.0-2.7 mm long. Hypanthium 1.6-2.6 mm long, 1.2-1.8 mm wide, narrowly obtriangular, glabrous or with very occasional short, sub-adpressed hair. Sepals broadly ovate, $1.6-2.2 \mathrm{~mm}$ 
long, $0.3-1.8 \mathrm{~mm}$ wide. Epicalyx segments narrowly lanceolate to more or less triangular, significantly narrower and shorter than the sepals, $0.4-1.4 \mathrm{~mm}$ long and $0.7-0.8 \mathrm{~mm}$ wide. Stipule lobes of basal leaves $11-19 \mathrm{~mm}$ long, $4-5 \mathrm{~mm}$ wide, apex obtuse/flat, denticulate, , up to 9 teeth, all with few, rather short hairs. Lobes glabrous, or nearly so; strongly tinged green distally, otherwise whitish. Base of plant whitish or greenish, occasionally flushed pink.

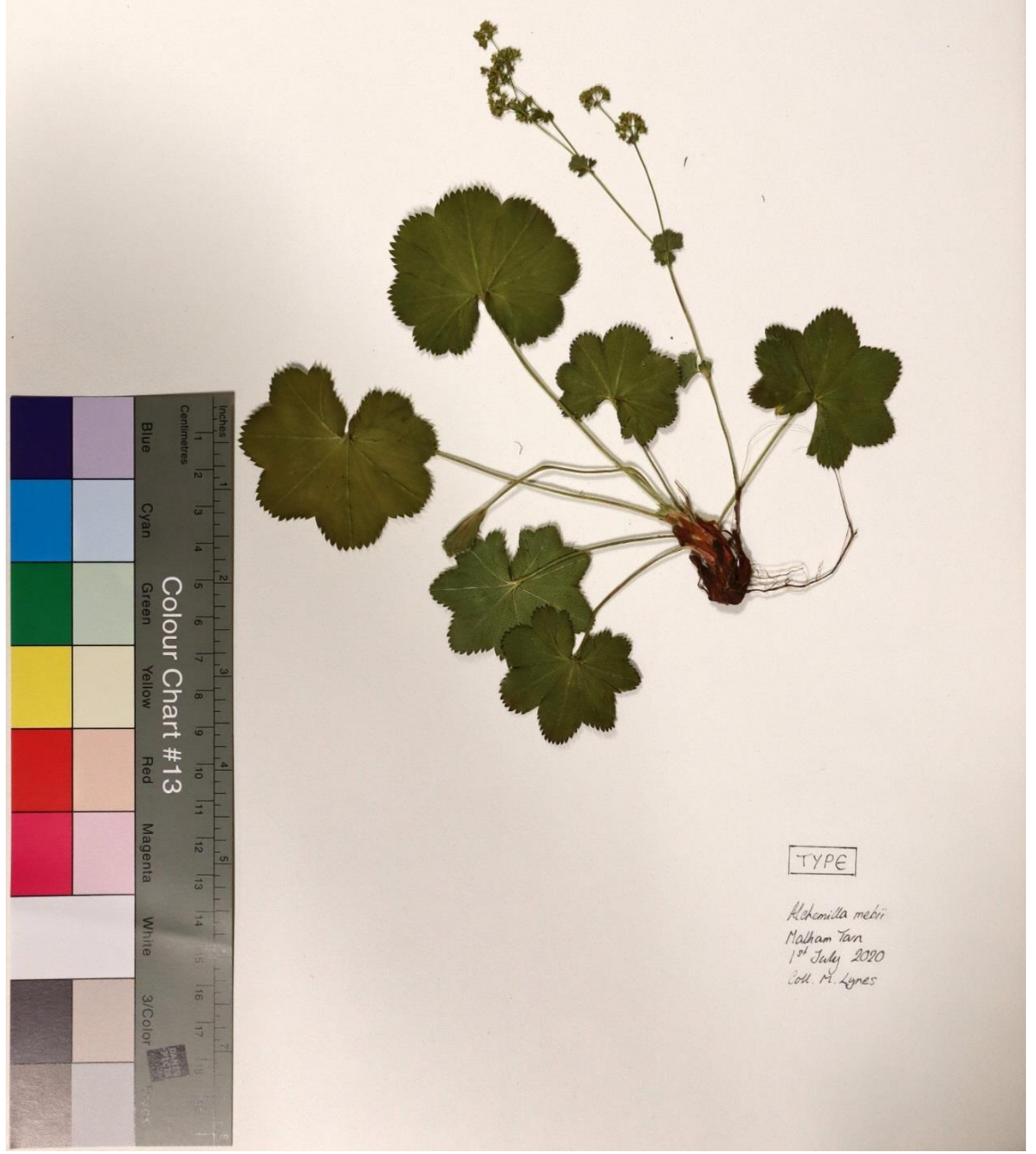

Figure 5. Holotype of Alchemilla mebii (LES) 


\section{History}

In the abstract to Part 2 of her seminal $A$. filicaulis papers (Bradshaw 1963a), in which she discusses the cytology of the taxon, MEB rather casually mentions that one plant of $A$. filicaulis had a chromosome count of $2 n=c .150$, completely different from the norm of $2 \mathrm{n}=105-110$.

In her 1959 PhD thesis, on which the papers are based, she states "Most interesting and surprising is the value $2 \mathrm{n}$ : 150-152 obtained for a subsp. filicaulis plant, ... which represents a Scottish mountain population. These plants have the usual subsp. filicaulis hair character and wine-red base, but the leaves have very short broad lobes and sharply pointed, somewhat connivent teeth, rather similar to A. wichurae; the leaves tend also to be shinier and crisper than in other subsp. filicaulis plants. They could easily be recognised in the field from amongst plants of A. vulgaris agg."

The Malham plant - here described as $A$. mebii - features rather more prominently in that it is specifically discussed in a separate, penultimate, section. Here she also mentions a dwarf $A$. glomerulans-type plant collected by Dr S.M. Walters on the slopes of Creag na Caillich, and having examined specimens of this plant in CGE, I considered the possibility this and the Malham plant were one and the same. It was this I had in mind when I first visited Creag na Caillich in mid-June 2013, the anomalous $A$. filicaulis specimen having quite slipped my mind. I soon encountered small, non-flowering, juvenile plants, albeit very few of them, which seemed a reasonable fit, and so I collected one for cultivation at home. The Alchemilla which subsequently developed and flowered, however, was quite unlike the Malham taxon, with its essentially glabrous leaves, with sharper somewhat connivent teeth and petiole/inflorescence stem indumentum, with relatively few, rather long and rather strongly erecto-patent hairs. The plant was somewhat reminiscent of $A$. filicaulis S.S., but it did not feel at all right for that taxon and I really did not know what to make of it.

In 2017 I became involved in a cytological study of Alchemilla taxa organised by the late Gerold Hügin. Specimens sent to Germany included the plant from Creag na Caillich, labelled ' $A$. filicaulis', as by that time I had convinced myself that is what it must be. On receipt of the results, it is this plant which has attracted Gerold's attention, the cytology being quite unlike any other $A$. filicaulis ever sampled.

On hastening to read once more the relevant section of her thesis, I knew instantly what my plant must be and that it was not $A$. filicaulis. Plans to visit Sweden in the summer of 2018 were put on hold and I went back to Ben Lawers NNR. Unfortunately, on that occasion, no more specimens were located. In 2019, however, through the generosity of Dan Watson and Sarah Watts, and with a National Trust for Scotland $4 \times 4$ vehicle, I was able to spend a full day on Creag na Caillich. Here Sarah and I found examples of what appeared to be the same taxon scattered over the eastern slopes of the hill.

MEB refers to the taxon as being common on the sheltered ledges used by sheep; however, this was not our experience. We found relatively few plants, the majority of which were immature, with even the few flowering plants rather dwarfed by grazing pressure. Two of the latter were collected for growing on and, on maturing in 2020, both proved identical to my 2013 collection and a good fit for the plants collected by MEB more than 70 years previously. Fortunately, on the same 
visit, a search of the slopes of Creag an Lochain found the plant was also present there, with mature plants locally frequent. Thus, was all eventually revealed.

\section{Habitat}

On Creag na Caillich it grows in flushed species rich Nardus grassland and on grassy ledges at the base of calcareous rocky outcrops, where conditions are sheltered and soil moisture content relatively high. On Creag an Lochain, where the exclusion of large herbivores has resulted in the tall herb community expanding into the grassland below cliff ledges (Watts et al., 2019), it is locally frequent within this tall herb community, with associated species including $A$. glabra, A. filicaulis, A. wichurae and $A$. glomerulans.

\section{Differences from other species}

As mentioned by MEB this species can usually easily be separated in the field from other native Alchemilla species, at least when mature. The shallowly lobed, frequently rather rounded leaves, with sharp, rather incurved teeth are superficially reminiscent of $A$. wichurae agg. (i.e. $A$. wichurae, $A$. oxyodonta, $A$. norvegica (Samuelsson, ined.), oleosa (Samuelsson, ined.) and similar taxa, some of which are also undescribed, which can quickly be discounted by the presence of patent to erecto-patent hairs, which also rule out $A$. glomerulans agg. (i.e. $A$. glomerulans, $A$. taernaensis Hyl. ex Ericsson \& S.Hellqvist and $A$. sciura Lynes) and $A$. glabra, which in any event is most unlikely to be confused with this species. $A$. monticola and $A$. propinqua both have leaves which are covered with patent hairs on both surfaces and hypanthia which are similarly much hairier, with the flowers of $A$. propinqua not infrequently 'doubled'. Both $A$. cymatophylla Juzepczuk, and $A$. subglobosa are similarly hairy and both are in any event quite unlike the subject plant. The most likely confusion species remains $A$. filicaulis var. filicaulis which shares with $A$. neomanifesta a rather sparse indumentum and base which may be tinged pink; however there the similarities largely end. A. filicaulis S.S. is usually a 'softer' plant overall and with a far more variable indumentum. However, beware plants growing in exposed, high-altitude situations which may have much 'harder', crisper, leaves than usual and which may also be extraordinarily glabrous. The indumentum of the upper leaf surface of $A$. neomanifesta is remarkably consistent with a sparse line of hairs almost invariably running down most of the folds, but otherwise essentially glabrous. Similarly on the under leaf surface, any hairs are confined to a few teeth either side of the distal end of veins and sometimes just onto the outer edges of the lobes. The leaf teeth of $A$. neomanifesta are noticeably deeper and frequently more incurved, almost wichurae-like (Fig. 6). Those of $A$. filicaulis shallower, more symmetrical, obtusely pointed, 'blunter' The leaves of $A$. neomanifesta are frequently almost semi-circular, appearing more rounded than $A$. filicaulis, which also has hairs which - when present - are typically patent and not erecto-patent and which on the inflorescence stem usually extend up to and including the $3^{\text {rd }}$ internode, whereas $A$. neomanifesta is more often glabrous beyond the $2^{\text {nd }}$. The stem leaves of $A$. neomanifesta are often almost flabellate, with a cuneate base, quite different from the usually more deeply-lobed leaves of filicaulis. The flowers are larger than those of $A$. vestita (2-3 $\mathrm{mm}$ ) and the pedicels noticeably shorter $(1.5-2 \mathrm{~mm})$ in $A$. vestita. The stipules of the basal leaves of $A$. neomanifesta usually lack pink, are slightly but usually visibly broader and with fewer teeth - up to 16 in $A$. filicaulis - whilst the 
adpetiolar cleft is noticeably shallower, and narrower. Whilst the base of $A$.

neomanifesta may be tinged pinkish, it is more typically whitish or greenish and - so far as is known - is never wine-red. In common with all the recently described species $A$. neomanifesta is very highly polyploid. Flow cytometry analysis has shown $A$. neomnifesta to have the highest known value of any UK species so far sampled. With a C-value of $0.72 \mathrm{pg}$ it is far more highly polyploid than $A$. filicaulis, at $0.44 \mathrm{pg}$ (G. Hügin pers. comm.).

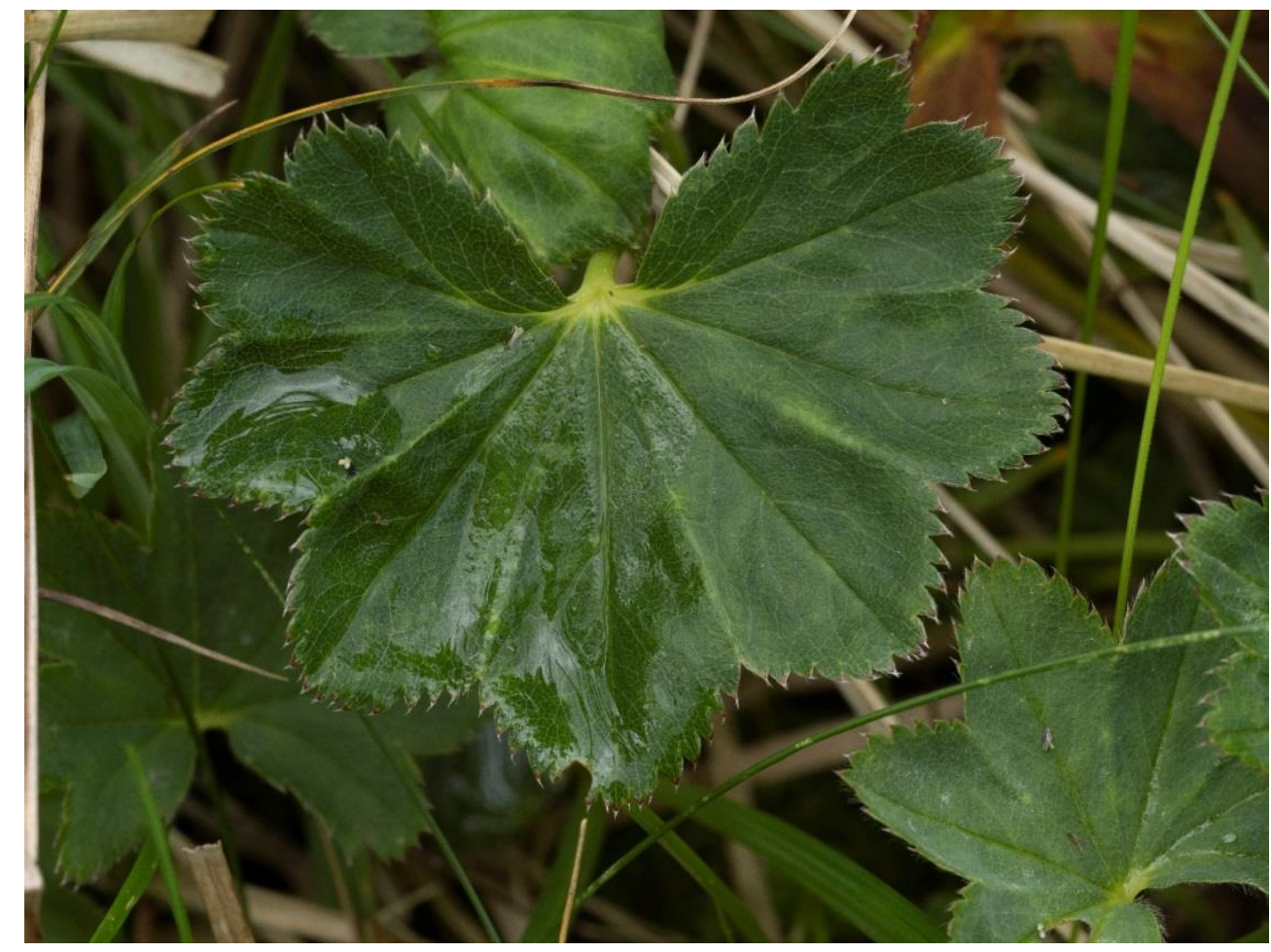

Figure 6. Typical, almost orbicular leaf of $A$. neomanifesta, the teeth inviting comparison with A. Wichurae.

\section{Etymology}

The specific epithet honours the history of the plant and uniquely among the newly described A/chemilla taxa (including $A$. sciura) is contrived from classic greco-latin; 'neomanifesta' - 'newly revealed'.

\section{Distribution and conservation status}

Currently known only from the eastern slopes of both Creag na Caillich and Creag an Lochain. At both sites it appears to be scarce; however, on Creag an Lochain, the population so far discovered consists of large, mature plants, quite unlike the small, largely juvenile plants on Creag na Caillich. The main threat to the species is undoubtedly grazing. MEB described the plant as common, at least on the sheltered ledges used by sheep, which she speculated had aided its dispersal. In 2019 most of these ledges were rather muddy and quite unsuitable for A/chemilla and it seems likely that over the intervening period the species has suffered due to continuing and ongoing grazing by excessive numbers of sheep and probaly also deer. Fortunately, the situation on Creag an Lochain is more promising. Here sheep were removed, and the area fenced in 2000 (Watts et al 2019); consequently, the habitat here is far 
more suitable, with vast swathes of $A$. glabra in particular, and probably the largest population of $A$. wichurae in the whole of Ben Lawers NNR. It seems likely that further investigations of the slopes here will reveal the species to be more numerous, at least it is to be hoped so.

A. neomanifesta is classified as IUCN Threat Category "Endangered" (IUCN 2001) due to the small known population size. There appears to be no immediate threat to its survival, albeit the known populations are small and fragmented, whilst that on Creag na Caillich has evidently declined significantly since its initial discovery.

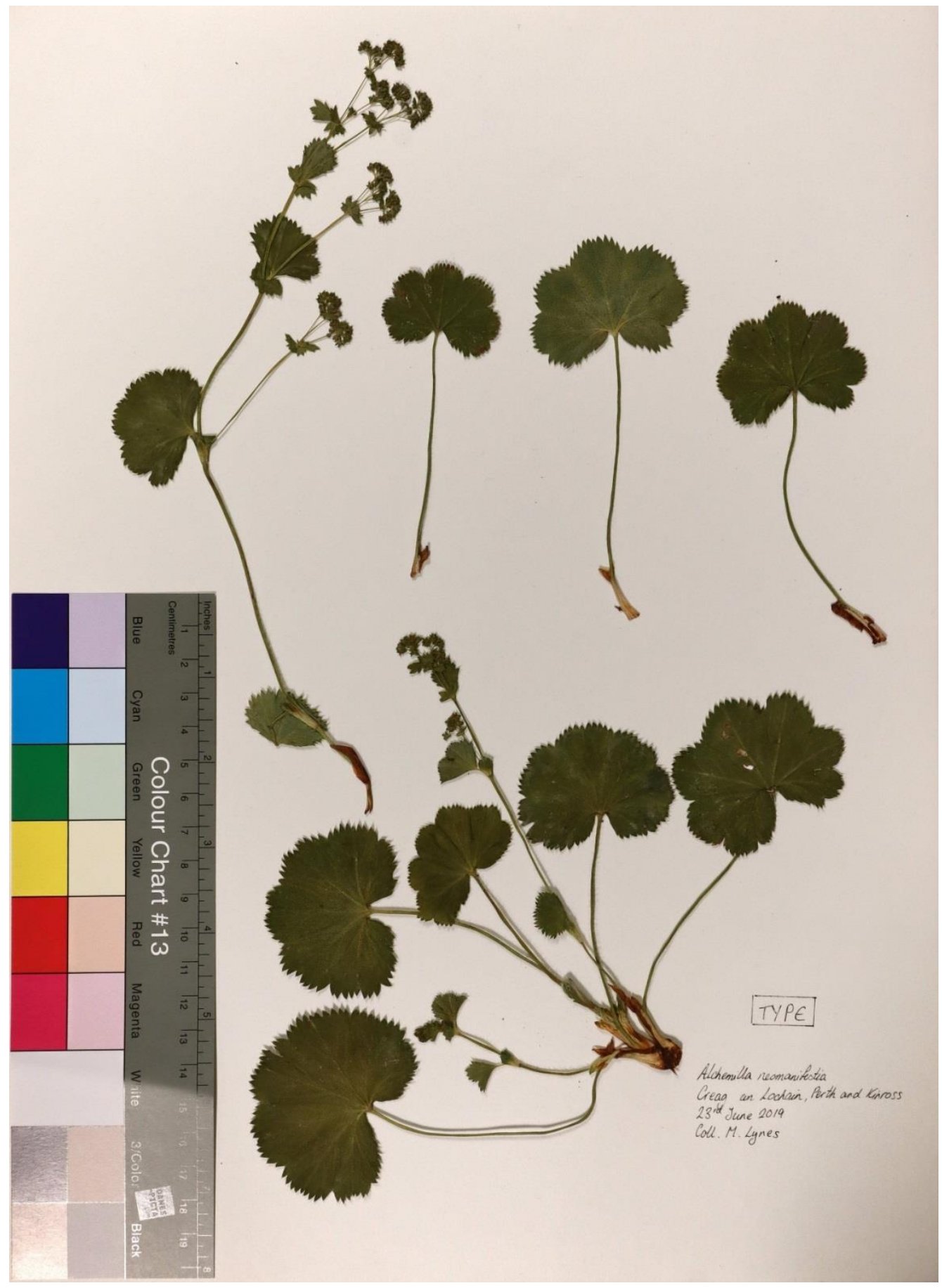

Figure 7. Holotype of Alchemilla neomanifesta (LES) 


\section{Acknowledgements}

Jeremy Roberts commented on and greatly improved an earlier draft. Hans Rydberg and Hasse Berglund guided me around Sörmland, while Olof Svensson kindly showed me the type locality for $A$. oxyodonta. Frances Graham and Sarah Watts provided ecological data. Les Tucker was instrumental in revealing that which I had thought hidden. The late Gerold Hügin arranged the flow cytometry analysis. Clare Brown (LES) expedited the accession of the type specimens and generously provided the relevant images used here. BSBI provided financial support for field work.

\section{References}

Bradshaw, M.E. 1959. Variation in Alchemilla vulgaris agg. Durham theses, Durham University. Available at Durham E-Theses Online: http://etheses.dur.ac.uk/8839/

Bradshaw, M.E. 1963a. Studies in Alchemilla filicaulis Bus. sensu lato and $A$. minima Walters. Introduction, and I. Morphological variation in $A$. filicaulis sensu lato. Watsonia 5: 304-320.

Bradshaw, M.E. 1963b. Studies in A/chemilla filicaulis Bus. sensu lato and A. minima Walters II. Cytology of $A$. filicaulis L., sensu lato. Watsonia 5: 321-326.

Bradshaw, M.E. 1964. Studies in Alchemilla filicaulis Bus. sensu lato and A. minima Walters III. Alchemilla minima. Watsonia 6: 76-81.

Lee, J. 2015. Yorkshire Dales. New Naturalist Library 130. London: HarperCollins. Lidberg, R \& Lindström, H. 2010. Medalpads Flora. Svenska Botaniska Föreningen.

Watts, S.H., Griffith, A., \& Mackinlay, L. 2019. Grazing exclusion and vegetation change in an upland grassland with patches of tall herbs. Appl. Veg. Sci. 2019; 00:1-11. https://doi.org/10.1111/avsc.12438

Copyright retained by author(s). Published by BSBI under the terms of the Creative Commons Attribution 4.0 International Public License.

ISSN: $2632-4970$

https://doi.org/10.33928/bib.2021.03.334 